\title{
Nutritional Status of Under Five Years Children in Rangpur Cantonment ${ }^{1}$
}

Hossain AKMA ${ }^{1}$, Ali ASMZ2 ${ }^{2}$, Nazrina S3, Hossain N4

DOI: https:/ / doi.org/ 10.3329/ jafmc.v15i2.50832

\begin{abstract}
Introduction: Nutrition is an important factor because of its role in preventing disease and infant survival and growth. Malnutrition and diseases are interlinked with each other and a great problem in all countries of the developing world.
\end{abstract}

Objectives: To assess the nutritional status of the under five year's children in Rangpur Cantonment.

Materials and Methods: This descriptive cross-sectional study was done in Children Welfare Centre (CWC) of Combined Military Hospital (CMH), Rangpur from July to August 2018. A total of 50 under five years children were selected and a structured questionnaire was used keeping the focus on socioeconomic status, dietary habits, hygiene practices, and anthropometric indices of the children.

Results: Out of 50 children, $60 \%$ were male and $40 \%$ were female. About $26 \%$ of children were in the 36 to 48 months of age group. About $50 \%$ were in the height group of $>100 \mathrm{~cm}, 34.0 \%$ were in the height group of $91-100 \mathrm{~cm}, 16 \%$ were in the height group up to 90 $\mathrm{cm}, 48.0 \%$ were in the weight group of $12.1-16 \mathrm{~kg}, 34.0 \%$ were in the weight group of $16 \mathrm{~kg}, 10 \%$ were in the weight group of 10.1-12 $\mathrm{kg}$ and $8 \%$ were in the weight group below $10 \mathrm{~kg}$.

Conclusion: In this study, $20 \%$ of cases were stunted and $80 \%$ of cases were not stunted and no wasted case was found and the overall prevalence of malnutrition in the Rangpur cantonment was low. A further in-depth study is recommended to draw conclusive inferences.

Key-words: Malnutrition, Poverty, Low birth weight.

\section{Introduction}

Nutrition is an important factor because of its role in preventing disease and infant survival and growth. Nutrition is the science of food and its relationship to health ${ }^{1}$. Malnutrition and diseases are interlinked with each other. Malnutrition in a child is the consequence of a range of factors, which are often related to poor food quality, insufficient food intake, and severe chronic infectious diseases. Insufficient nutrition leads to stunted growth and increased morbidity and mortality among infants and also decreased the survival chances of adults later in life. In developing countries, the prevalence of stunting is estimated at 165 million children below five years of age due to poor feeding and chronic infections. So, reduction in morbidity and improvement in nutritional status are major policy issues for health planners in less developed countries. Poor nutrition severely hinders personal, social, and national development. Infant mortality rate that is mortality during the first year of life is an important indicator for describing the overall social and economic well-being of a country. In the world, Singapore has the lowest infant mortality rate which is $2.4 / 1000$ live births. In developing countries ${ }^{2}$ infant mortality rates are high, like India $34 / 1000$ live births in 2016, Myanmar 40.1/ 1000 live births in 20016, Bangladesh $28.2 / 1000$ live births in 2016. The nutritional status of under-five year's children is of particular concern since the early years of life are crucial for future growth and development. Globally, nutritional status is considered the best indicator of the wellbeing of young children 3 . As a result of overcrowding, unemployment, poverty, and poor access to adequate food as well as health services, infectious diseases and malnutrition are common in Bangladesh. It is noted that increased morbidity among children living in poverty is strongly linked to malnutrition and an inadequate diet.

Bangladesh is experiencing rapid development, both economically and socially which is altering infant feeding practices. The lifestyle of many mothers who used to stay home but now are entering the workforce is likely to affect the nutritional status of infants. Mothers in deprived socio-economic conditions frequently have low birth weight (weight of the infant at birth less than 2,500 grams) infants. In Bangladesh, 50\% of the babies are with low birth weight due to malnutrition of mothers ${ }^{4}$. The infant's low birth weight stems primarily from the mother's malnutrition and poor health over a long period including during pregnancy, the high prevalence of specific and nonspecific infections, or from pregnancy-related complications. In developing countries, the most important socio-economic trains in achieving proper nutrition are poverty 5 . Bangladesh is one of the poorest developing countries in the world and 49.73 million peoples are living below the poverty line ${ }^{6}$. As a result of deep and widespread poverty, overcrowding, unemployment, and poor access to health services, chronic infectious diseases and malnutrition are common in society. Mortality and morbidity among poor children are increased, which is strongly linked to malnutrition and an inadequate diet?. The percentage of children under five years of age with stunting is $42.4 \%$ in 2005 and underweight is $47.8 \%$ in 2005 and wasting is $12.7 \%$ in $2005^{3}$. The prevalence of malnutrition will be assessed by three standard anthropometric indicators: underweight, stunting, and wasting, following the WHO guidelines and cut-off points ${ }^{8}$. The present study will enrich our knowledge about the prevalence of malnutrition among the under five years children at Rangpur Cantonment.

\section{Materials and Methods}

This was a descriptive cross-sectional non-comparison study carried out at CWC of $\mathrm{CMH}$, Rangpur. The study was conducted among 50 children aged 12 months to less than five years by a selfadministered questionnaire. Anthropometric indices such as weight, height, and Mid Upper Arm Circumference (MUAC) were included in the questionnaire. Purposive sampling was used to select the study group. A total of 50 women were selected who had twelve months to less than five years children for data collection. Among 50 children, 30 were males and 20 were females. Confidentiality was

1. Lt Col AKM Alamgir Hossain, MBBS, MPH, Commanding Officer, 10 Field Ambulance, Rangpur 2. Col ASM Zulfiquer Ali, MBBS, MPH Assistant Director of Medical Services, 66 Infantry Division, Rangpur 3. Lt Col Sayeda Nazrina, MBBS, MPhil, Associate Professor 0 Pharmacology, AFMC, Dhaka 4. Dr Nusrat Hossain, MBBS, FCPS (Gynae \& Obs), Junior Consultant of Gynaecology, Pirgasa Upazilli Health Complex, Rangpur. 
duly ensured to all participants and informed consent was obtained. After the collection of data, it was scrutinized, edited, and verified for its consistency. Data analysis was done by computer using SPSS 23 and presented in figures and tables.

\section{Results}

Out of 50 children, 30 were male and 20 were female with male to female ratio was 1.5:1. Most of the children were Colostrum fed and exclusively breastfed by their mother which were $42(84 \%)$ and $45(90 \%)$ respectively (Table-I). Most of the father of under five years children were noncommissioned officer(NCO)s which was 30(60\%) followed by Sainiks, noncommissioned enrolled (NCE)s and junior commissioned officer(JCO)s which were 9(18\%), 6(12\%), 5(10\%) respectively. Among the 30 males, 5(16.67\%) cases were in the age group of 12 months, $4(13.33 \%)$ cases were in the age group of 12.1 to 24 months, $5(16.67 \%)$ cases were in the age group of 24.1 to 36 months, $7(23.33 \%)$ cases were in the age group of 36.1 to 48 months and $9(30.0 \%)$ cases were in the age group of 48.1 to below 60 months. Among the 20 females, 3(15\%) cases were in the age group of 12 months, $3(15 \%)$ cases were in the age group of 12.1 to 24 months, $5(25 \%)$ cases were in the age group of 24.1 to 36 months, $6(30 \%)$ cases were in the age group of 36.1 to 48 months and $3(15 \%)$ cases were in the age group of 48.1 to below 60 months (Table-II). The study revealed that $25(50 \%)$ cases were in the height group of $>100 \mathrm{~cm}$ followed by $17(34.0 \%)$ cases were in the height group of $91-100 \mathrm{~cm}$ and $08(16 \%)$ cases were in the height group up to $90 \mathrm{~cm}$. The study also revealed that $24(48.0 \%)$ cases were in the weight group of $12.1-16 \mathrm{~kg}$ followed by $17(34.0 \%)$ cases were in the weight group of $16 \mathrm{~kg}$ and $5(10 \%)$ cases were in the weight group of $10.1-12 \mathrm{~kg}$, and $4(08 \%)$ cases were in the weight group below 10 $\mathrm{kg}$ (Table-III). The study revealed that $10(20 \%)$ cases were stunted and $40(80 \%)$ were not stunted and no wasted case was found (Table-IV).

Tabel-I: Distribution of under five children according to feeding practices $(n=50)$

\begin{tabular}{|l|c|c|}
\hline \multicolumn{1}{|c|}{ Variables } & Given (\%) & Not given (\%) \\
\hline Colostrum feeding & $42(84)$ & $8(16)$ \\
\hline $\begin{array}{l}\text { Exclusive } \\
\text { breastfeeding }\end{array}$ & $45(90)$ & $5(10)$ \\
\hline
\end{tabular}

\section{$60 \%$}

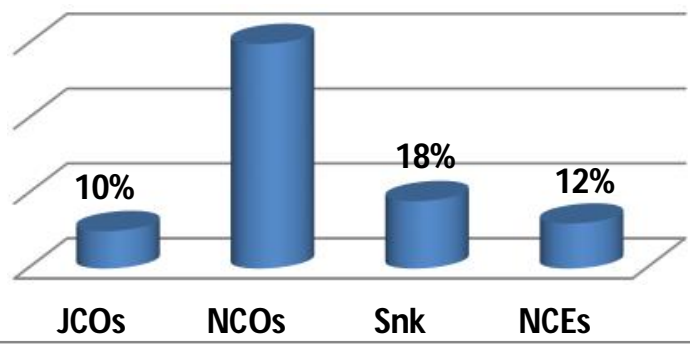

Figure-I: Distribution of occupation of father

Table-II: Distribution of age and sex of the respondents $(n=50)$

\begin{tabular}{|l|c|c|c|}
\hline \multicolumn{1}{|c|}{$\begin{array}{c}\text { Age in } \\
\text { months }\end{array}$} & $\begin{array}{c}\text { Male } \\
\mathrm{n}(\%)\end{array}$ & $\begin{array}{c}\text { Female } \\
\mathrm{n}(\%)\end{array}$ & $\begin{array}{c}\text { Total } \\
\mathrm{n}(\%)\end{array}$ \\
\hline $10-12$ & $05(16.67)$ & $03(15)$ & $08(16)$ \\
\hline $12.1-24$ & $04(13.33)$ & $03(15)$ & $07(14)$ \\
\hline $24.1-36$ & $05(16.67)$ & $05(25)$ & $10(20)$ \\
\hline $36.1-48$ & $07(23.33)$ & $06(30)$ & $13(26)$ \\
\hline $48.1-<60$ & $09(30.00)$ & $03(15)$ & $12(24)$ \\
\hline Total & $30(100)$ & $20(100)$ & $50(100)$ \\
\hline
\end{tabular}

Table-III: Distribution respondents by height and weight $(\mathrm{n}=50)$

\begin{tabular}{|l|l|c|c|}
\hline \multicolumn{2}{|c|}{ Variable } & Frequency & Percentage \\
\hline \multirow{3}{*}{$\begin{array}{l}\text { Height } \\
(\mathrm{cm})\end{array}$} & $\leq 90$ & 08 & 16.0 \\
\cline { 2 - 4 } & $91-100$ & 17 & 34.0 \\
\cline { 2 - 4 } & $\geq 100$ & 25 & 50.0 \\
\hline \multirow{4}{*}{$\begin{array}{l}\text { Weight } \\
\text { (Kg) }\end{array}$} & $\leq 10.0$ & 04 & 08.0 \\
\cline { 2 - 4 } & $10.1-12.0$ & 05 & 10.0 \\
\cline { 2 - 4 } & $12.1-16.0$ & 24 & 48.0 \\
\cline { 2 - 4 } & $\geq 16.0$ & 17 & 34.0 \\
\hline
\end{tabular}

Table-IIV: Distribution of stunting and wasting by Water low's classification

\begin{tabular}{|l|c|c|c|c|c|c|}
\hline \multirow{2}{*}{ Height for age } & \multicolumn{9}{|c|}{ Weight for height } \\
\cline { 2 - 7 } & \multicolumn{2}{|c|}{ Both sexes $(\mathrm{n}=50)$} & \multicolumn{2}{c|}{ Male $(\mathrm{n}=30)$} & \multicolumn{2}{c|}{ Female $(\mathrm{n}=20)$} \\
\cline { 2 - 7 } & $\begin{array}{c}\text { Wasted } \\
<95.0 \%\end{array}$ & $\begin{array}{c}\text { Not wasted } \\
\geq 95.0 \%\end{array}$ & $\begin{array}{c}\text { Wasted } \\
<95.0 \%\end{array}$ & $\begin{array}{c}\text { Not wasted } \\
\geq 95.0 \%\end{array}$ & $\begin{array}{c}\text { Wasted } \\
<95.0 \%\end{array}$ & $\begin{array}{c}\text { Not wasted } \\
\geq 95.0 \%\end{array}$ \\
\hline Stunted $(<95.0 \%)$ & 00 & 10 & 00 & 06 & 00 & 04 \\
\hline Not stunted $(>95.0 \%)$ & 00 & 40 & 00 & 24 & 00 & 16 \\
\hline Total & $\mathbf{0 0}$ & $\mathbf{5 0}$ & $\mathbf{0 0}$ & $\mathbf{3 0}$ & $\mathbf{0 0}$ & $\mathbf{2 0}$ \\
\hline
\end{tabular}

\section{Discussion}

In Bangladesh, 49.73 million peoples are living below the poverty line. Overcrowding, unemployment, poverty and poor access to adequate food as well as health services, infectious diseases, and malnutrition are common in this society. It is noted that increased morbidity among children living in poverty is strongly linked to malnutrition and an inadequate diet ${ }^{3}$. The study revealed that Colostrum was fed by a 
mother in $84 \%$ of cases and a total of $90 \%$ had a history of exclusive breastfeeding. Exclusive breastfeeding gives immunity to the child as well as neurodevelopment. Most of the fathers of under five years children were NCOs which was $60 \%$ followed by Sainiks, NCES, and JCOs which were 18\%,12\%, 10\% respectively. The study also revealed that 30 cases were male and 20 cases were female with male to female ratio was 1.5:1. Among the 30 male, $16.67 \%$ cases were in the age group of 10 to 12 months, $13.33 \%$ cases were in the age group of 12.1 to 24 months, $16.67 \%$ cases were in the age group of 24.1 to 36 months, $23.33 \%$ cases were in the age group of 36.1 to 48 months and $30.0 \%$ cases were in the age group of 48.1 to $<60$ months. Among the 20 females, $15 \%$ cases were in the age group of 10 to 12 months, $15 \%$ cases were in the age group of 12.1 to 24 months, $25 \%$ cases were in the age group of 24.1 to 36 months, 30\% cases were in the age group of 36.1 to 48 months and $15 \%$ cases were in the age group of 48.1 to $<60$ months.

Among the 50 under five years children, $50 \%$ cases were in the height group of $>100 \mathrm{~cm}$ followed by $34.0 \%$ cases were in the height group of $91-100 \mathrm{~cm}$ and $16 \%$ cases were in the height group up to $90 \mathrm{~cm}$. The study revealed that $48.0 \%$ cases were in the weight group of $12.1-16 \mathrm{~kg}$ followed by $34.0 \%$ cases were in the weight group of $16 \mathrm{~kg}$ and 10\% cases were in the weight group of 10.1-12 $\mathrm{kg}$ and $08 \%$ cases were in the weight group below $10 \mathrm{~kg}$. Another study reported that the prevalence of wasting $(W / H)$, stunting $(H / A)$, and underweight (W/A) among the children (0-60 months) were $23.4 \%, 26.7 \%$, and $37.8 \%$ respectively taking both heights for age (stunting) and weight for height (wasting) into consideration, 55.0\% of the children could be classified as normal7. In this study, $20 \%$ of cases were stunted and $80 \%$ cases were not stunted and no wasted case was found by Waterlow's classification. This finding is contradicted with Yusuf et al9 ${ }^{9}$. The overall prevalence of malnutrition in Rangpur Cantonment was low. This is contradicted with NCHS reference classification, where $34 \%$ of the children were stunted, $30 \%$ children were wasted and $46 \%$ children were under weight ${ }^{10}$. This may be because the sample of the present study was small and did not represent the whole country.

\section{Conclusion}

In this study the overall prevalence of malnutrition of under five years children in Rangpur Cantonment was low and no underweight and no wasted children were found because the children came from urban defense service families having the benefits of a good house in the cantonment and getting the facilities of rations, medical facilities, playground and amusement park at the doorstep. In this study due to the above-mentioned cause, the prevalence of malnutrition under five years children was lower than in other national studies.

\section{References}

1. Park K. Preventive and Social Medicine, 22nd Ed, 2013:563.

2. Infant mortality rate by country: Thematic Map - Asia - Index Mundi. Available at <http s://www. indexmundi.com /map/ ?t=0\&v= $29 \& r=$ as \&l=en $>$ [Accessed 25 Sep 2018].

3. Rahman M, Mostofa G, Nasrin SO. Nutritional status among children aged 24-59 months in rural Bangladesh: An assessment measured by BMI index. The Internet Journal of Biological Anthropology 2009; 3(1):1-7.

4. Bari MA. Impact of nutrition education and financial assistance to the landless rural mothers in terms of nutritional status of there under 5 children in a selected area in Kapasia. A dissertation for MPH (Health Education) session 1994, National Institute of Preventive and Social Medicine (NIPSOM).

5. Pellet PL: Malnutrition, wealth and development. Food Nutr Bull 1981; 31:17-9.

6. Bangladesh Bureau of Statistics. Child Nutrition Survey of Bangladesh, Dhaka, Bangladesh, 1994.

7. Sultana W. Nutritional Status and Dietary Pattern of Under-5 Children of Dhaka University Employees Belonging to Low Socioeconomic Status. [Dissertation]. MSc in Nutrition. Institute of Nutrition and Food Science, Dhaka University, 1995.

8. WHO. Measuring change in nutritional status. Geneva, 1983.

9. Yusuf HKM, Salamatullah Q, Islam MN and Hoque T. (Eds). Report of the National IDD Survey in Bangladesh, 1993. Dhaka University.

10. INFS. Nutrition Survey of Rural Bangladesh (1981-82). Dhaka, Bangladesh, 1983. Available at <https://www.google.com/search? client> [Accessed 25 Sep 2018]. 